\title{
Estimation of the net primary productivity of forests on age in China
}

\author{
Hao $\mathrm{Wu}^{1,2, \mathrm{a}}$, Tao Zhou ${ }^{1,2, \mathrm{~b}^{*}}$, Hui Luo ${ }^{1,2, \mathrm{c}}$ \\ ${ }^{1}$ State Key Laboratory of Earth Surface Processes and Resource Ecology, Beijing Normal \\ University, Beijing, China \\ ${ }^{2}$ Academy of Disaster Reduction and Emergency Management, Ministry of Civil Affairs and Ministry \\ of Education, Beijing, China

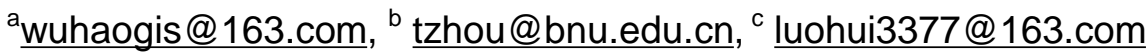

Keywords: NPP, Forests age, Maximum light-use efficiency

Abstract. Under the background of global change, the internal relationship between forests' age and forests' carbon cycling is very important to study the position and function of forests in the global carbon cycle.Thus, the study employed field observations to inversely estimate the parameter of maximum light-use efficiency $\left(\varepsilon_{\max }\right)$ of forests in different stand ages, generated a national map of forests' NPP on forests age.We found the $\varepsilon_{\max }$ has decreased with the increased of forest ages that is consistent with other studies, and compared with the fixed $\varepsilon_{\max }$, the NPP of forests was calculated on forests age are more reliable and stable.The results shows a significant heterogeneity of forests' NPP_age, and the average NPP of the evergreen broadleaf forest, the deciduous broadleaf forest, evergreen needleleaf forest and deciduous needleleaf forests is about 377.34, 293.99,273.63 and $306.36 \mathrm{gC} / \mathrm{m}^{2} \bullet \mathrm{yr}$.On the national level, the forests' $\mathrm{NPP}$ age was $303.45 \mathrm{C} / \mathrm{m}^{2} \bullet \mathrm{yr}$ in China. In the future, the forests' age needs to be taken into account in the Estimation of the net primary productivity.

\section{INTRODUCTION}

The growth status of forestsis an important factor to determine the position of forests in the global carbon cycle[1]. Net primary productivity (NPP) not only directly reflects the forests in the natural environment conditions, the production capacity, characterization of forest growth[2], which also is the main index to establish the biological process model to predict and forecast the carbon cycle [3]. However, there is little understanding of the response of forests' growth to environmental change[4]. Under the background of global change, revealing the internal relationship between forests' age and forests' carbon cycling, it is very important to study the position and function of forestsin the global carbon cycle [5, 6].

The remotely sensed forest NPP and NPP_obs retrieved from field observations were used, and a relationship between the maximum light-use efficiency and the forest stand ageswas generated in the study. The forests age in this relationships as an intermediate parameter for major forest types in China.

\section{DATA AND METHODS}

\section{DATA}

(1) Remote sening data.The Global Inventory Modeling and Mapping Studies (GIMMS) normalized difference vegetation index (NDVI) data sets (monthly, $8 \mathrm{~km} \times 8 \mathrm{~km}$, January 1982 to 
December 2013) were generated to provide a 32-year satellite record of monthly changes in terrestrial vegetation $^{[7]}$. ENREF 7

(2)Field observation data of NPP.The field observation data of NPP contained extensive records of forest stands (10 m $\times 10 \mathrm{~m}$ plots) across China[8]. The database records included a total of 6153 forest stands.

(3) Meteorological data.The temperature and precipitation data were got from Climatic Research Unit (CRU) $\left(0.5^{\circ} \times 0.5^{\circ}, 1982 \sim 2013\right)$. Total monthly solar radiation derived from 726 meteorological stations. This data were interpolated $0.0833^{\circ} \times 0.0833^{\circ}$ used the Kriging method and a new interpolation base on digital elevation model.

(4) The vegetation data.The digitized vegetation map (1: 4,000,000) was acquired from Environmental and Ecological Science Data Center for West China, National Natural Science Foundation of China [9]. In the vector map, vegetation types in China were classified as follows: Evergreen broadleaf forest (EBF), Deciduous broadleaf forest (DBF) ,Evergreen needleleaf forest (ENF), Deciduous needleleaf forest (DNF), Mixed forest(MF).

(5) The forest stand ages data.The Spatial pattern of forests' ages in China with a spatial resolution of eight kilometer came from the Academy of Disaster Reduction and Emergency Management of Civil Affairs \& Ministry of Education(ADREM) [10]. The average forests' age was 40.6 years in China, the main forests' age was ranged from 10 to 80 years.

\section{Methods}

\section{CASA model}

Carnegie-Ames-Stanford Approach (CASA) model [11] can estimate monthly NPP with satellite data, monthly temperature, precipitation and soil properties [12].

In this study, the CASA method of _Zhu [13] was used to calculate vegetation NPP. In small scale of area, the NPP equals the amount of photosynthetically active radiation that absorbed by green vegetation (APAR) $\left(\mathrm{g} \mathrm{C} \cdot \mathrm{MJ}^{-1} \cdot \mathrm{month}^{-1}\right), \quad$ multiplied by the actual light use efficiency $(\varepsilon)(\mathrm{g}$ $\left.\mathrm{C} \cdot \mathrm{MJ}^{-1}\right)$, which the radiation is converted to plant biomass increment. Where $\mathrm{x}$ is a pixel of remote sensing image, and $t$ is the period of NPP, such as a month.

$\operatorname{NPP}(x, t)=\operatorname{APAR}(x, t) \times \varepsilon(x, t)$

$$
\operatorname{NPP}(x, t)=\operatorname{APAR}(x, t) \times \varepsilon(x, t)
$$

\section{Maximum light-use efficiency $\left(\varepsilon_{\max }\right)$ of forests' age in China}

(1) The estimation of NPP on the CASA model is largely affected by the maximum light-use efficiency $\left(\varepsilon_{\max }\right)$. In this study, 4821 sampling plots that both have stand biomass and forests' age data were selected from 6153 sampling plots. These data were randomly divided into two groups: experimental group and validation group.

$$
\varepsilon_{\mathrm{max}}=\frac{N P P_{0 \mathrm{bg}} * \pi_{T s}}{N P P_{\mathrm{rg}}}
$$

(2) In this study, the experimental group to correct the $\varepsilon_{\max } \varepsilon_{\max }$ for all forest types, where $\mathrm{NPP}_{\text {obs }} N P P_{\text {obs }}$ is the field observation data of NPP. The $\mathrm{NPP}_{\mathrm{obs}} N P P_{\text {obs }}$ is separated by the forest types and the forest stand ages, the forest stand ages were separated into 23 groups(10 years interval classification, more than 220 years were divided into as group 23). Each group of data below 2 samples is not involved in the process. 
$N P P_{r z} \mathrm{NPP}_{\mathrm{rs}}$ is the estimated NPP based on the meteorological data and the remote sensing data (NDVI). $\varepsilon_{\mathrm{rs}} \varepsilon_{r s i s}$ the fixed value for all the forest types and all the forest age, and which value is 0.389.The value of $\varepsilon_{\max }$ is various from different forest types and the forest stand ages according to the $\mathrm{NPP}_{\text {obs }}$ group.

(3) According to the $\varepsilon_{\max }$ of the experimental group, the forest age-forest vegetation maximum NPP model was calculated and compared with the NPP data of ground observation in the validation group.

\section{RESULTS and DISCUSSION}

The relationship between the maximum light-use efficiency $\left(\varepsilon_{\max }\right)$ and the forest ages
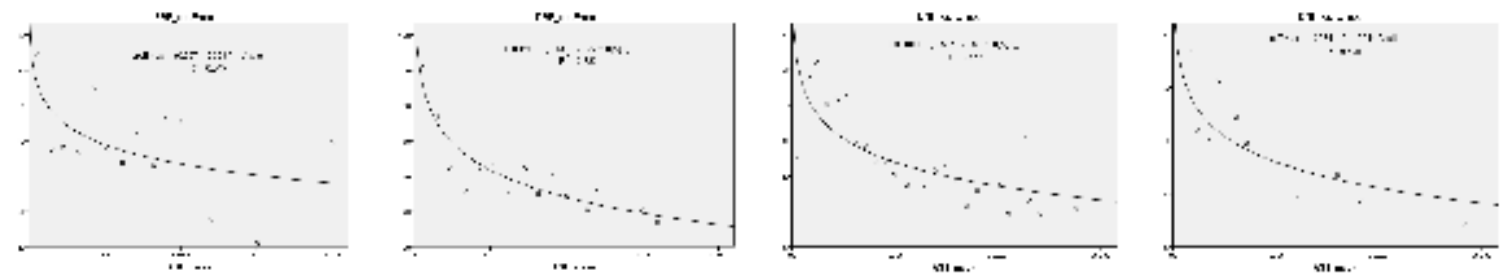

Fig.1. The relationship between the forest stand age and the $\varepsilon_{\max }$ of four forest types
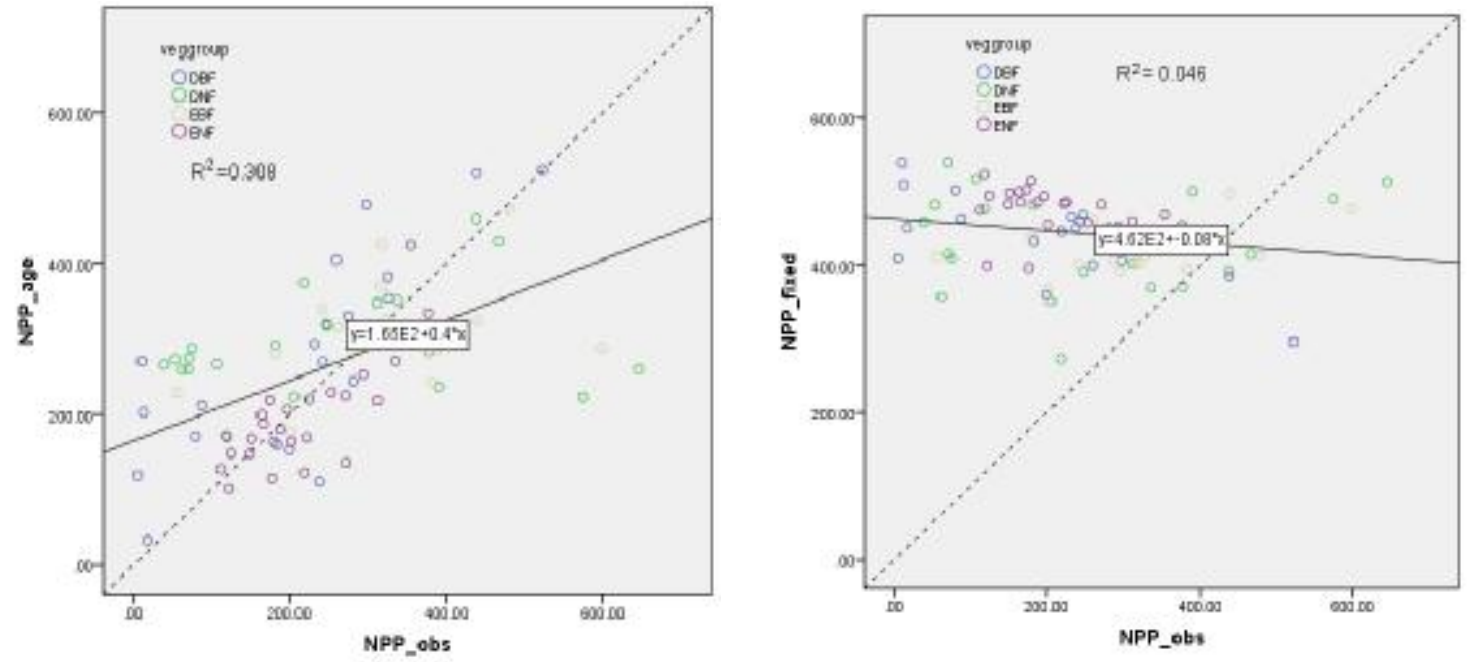

Fig.2.The relationship between NPP_age and NPP_fixed of four forest types.

The results show that the maximum light use efficiency was decreased with the increased of forest ages in EBF, DBF, ENF and DNF(Fig.1), which is consistent with the findings of Li,. et al. [6, 14] . MF had little measured data in this study. Their (MF) was calculated with some data from references. The mean observed NPP of MF was 0.389. As shown in the Fig.2, the decisive coefficient $\mathrm{R}^{2}$ between NPP_age and measured data NPP_obs increased from 0.046 to 0.308 , which passed the significant test. The result show that the NPP of forests was calculated on forests age are reliable and stable.

\section{The forests'NPP_age in China}

The results indicate that the spatial distribution of forest NPP_age have significant heterogeneity. From the national level, the forest NPP_age was $303.45 \mathrm{C} / \mathrm{m}^{2} \cdot \mathrm{yr}$ in China. The forests' NPP_age over $500 \mathrm{C} / \mathrm{m}^{2} \cdot \mathrm{yr}$ are mainly distributed in central Hainan, southwestern Yunnan and south Tibet. The forests' NPP_age of the western Guangdong, central Guangxi, eastern Yunnan and south 
Sichuang are mostly range from 350 to $500 \mathrm{gC} / \mathrm{m}^{2} \cdot \mathrm{yr}$. In the northeast China, deciduous broad-leaved forest are widely distributed in the large and small Xinganling Mountains and Changbai Mountain range, and the forest NPP value is mainly range from $200 \mathrm{gC} / \mathrm{m}^{2} \cdot \mathrm{yr}$ to $350 \mathrm{gC} / \mathrm{m}^{2} \cdot \mathrm{yr}$, partly in temperature and precipitation. There are still some forests' of NPP_age value are higher than $350 \mathrm{gC} / \mathrm{m}^{2} \cdot \mathrm{yr}$, which because the photosynthetic efficiency of the forests is higher than other forests that with low age. In the central and eastern provinces of Hunan, Jiangxi, Fujian and Zhejiang, forest types are deciduous broad-leaved forests and deciduous coniferous forests, the forest NPP_age was 200 to $400 \mathrm{gC} / \mathrm{m}^{2} \cdot \mathrm{yr}$ and the forests are young. The forest NPP_age of northwest China is lower than that ofother regions in China, and the average values ranging from 5 to $15 \mathrm{C} / \mathrm{m}^{2} \cdot \mathrm{yr}$ because low temperature and drought.

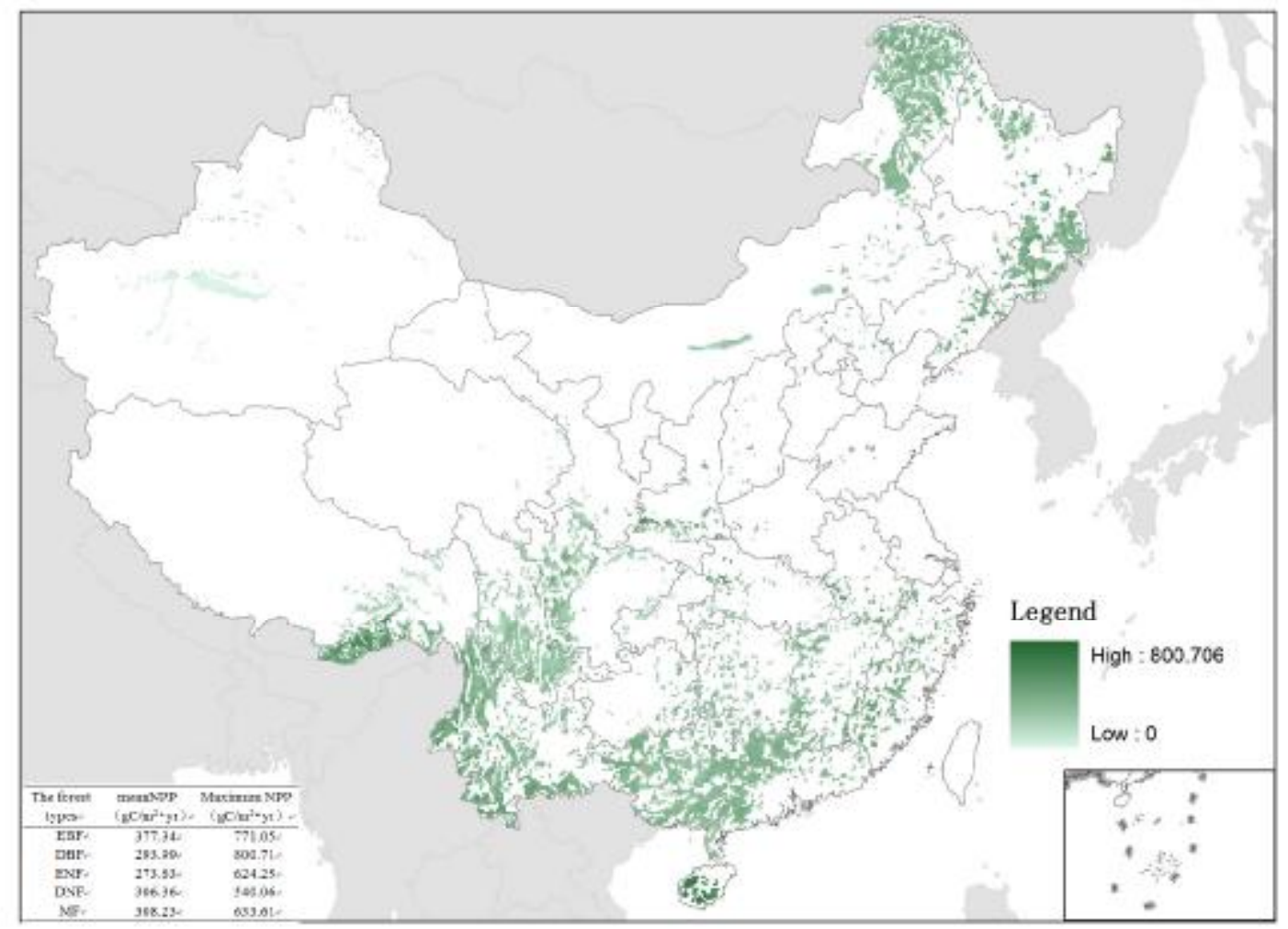

Fig.3.The distribution of NPP based on the forests age from 1982 to 2013

Estimated the NPP based on the forests agevary from different forest types. During the period 1982 to 2013, and the average NPP of the evergreen broadleaf forest, the deciduous broadleaf forest, evergreen needleleaf forest is about $377.34,293.99$ and $273.63 \mathrm{gC} / \mathrm{m}^{2} \bullet \mathrm{yr}$, respectively, the average NPP of the evergreen needleleaf forests is less than each other. Compared with other forest types, the maximum forest NPP_age of DBF is the highest $\left(800.71 \mathrm{gC} / \mathrm{m}^{2} \cdot \mathrm{yr}\right)$ while the maximum forest NPP_age of DNF is the lowest $\left(540.06 \mathrm{gC} / \mathrm{m}^{2} \bullet \mathrm{yr}\right)$. Thus, the maximum forest NPP_age shows: $\mathrm{DBF}>\mathrm{EBF}>\mathrm{ENF}>\mathrm{MF}>\mathrm{DNF}$.

\section{References}

[1] Ryan MG, Binkley D, Fownes JH. Age-Related Decline in Forest Productivity: Pattern and Process. Advances in Ecological Research 1997;27:213.

[2] Steffen W, Noble I, Canadell J, Apps M, Schulze ED, Jarvis PG. The terrestrial carbon cycle: Implications for the Kyoto Protocol. Science 1998;280:1393.

[3] Stephenson NL, Das AJ, Condit R, Russo SE, Baker PJ, Beckman NG, et al. Rate of tree carbon accumulation increases continuously with tree size. Nature 2014;507:90.

[4] Ruizbenito P, Madrigalgonzález J, Young S, Mercatoris P, Cavin L, Huang TJ, et al. Climatic 
Stress during Stand Development Alters the Sign and Magnitude of Age-Related Growth Responses in a Subtropical Mountain Pine. Plos One 2014;10:1063.

[5] Zhang C, Ju W, Chen JM, Li D, Wang X, Fan W, et al. Mapping forest stand age in China using remotely sensed forest height and observation data. Journal of Geophysical Research: Biogeosciences 2014;119:1163.

[6] Zhou T, Shi P, Jia G, Dai Y, Zhao X, Shangguan W, et al. Age - dependent forest carbon sink: Estimation via inverse modeling. Journal of Geophysical Research: Biogeosciences 2015.

[7] Zhu Z, Bi J, Pan Y, Ganguly S. Global Data Sets of Vegetation Leaf Area Index (LAI)3g and Fraction of Photosynthetically Active Radiation (FPAR)3g Derived from Global Inventory Modeling and Mapping Studies (GIMMS) Normalized Difference Vegetation Index (NDVI3g) for the Period 1981 to 20. Remote Sensing 2013;5:927.

[8] Guo Q, Ren H. Productivity as related to diversity and age in planted versus natural forests. Global Ecology and Biogeography 2014;23:1461.

[9] Hou H. Vegetation atlas of China (1：400 000 000). Science Press China; 1980.

[10]Dai MZ, Tao. Spatial pattern of forest ages in China retrieved from national?level inventory and remote sensing imageries. 2011.

[11] Potter CS, Rerson JT, Field CB, Matson PA, Vitousek PM, Mooney HA, et al. Terrestrial ecosystem production: A process model based on global satellite and surface data. Global Biogeochemical Cycles 1993;7:811.

[12]Zhang LX, Zhou DC, Fan JW, Hu ZM. Comparison of four light use efficiency models for estimating terrestrial gross primary production. Ecological Modelling 2015;300:30.

[13]Zhu WQ, Pan YZ. ESTIMATION OF NET PRIMARY PRODUCTIVITY OF CHINESE TERRESTRIAL VEGETATION BASED ON REMOTE SENSING. Journal of Plant Ecology 2007;31:413.

[14]Li Z, Zhou T. OPTIMIZATION OF FOREST AGE-DEPENDENT LIGHT-USE EFFICIENCY AND ITS IMPLICATIONS ON CLIMATE-VEGETATION INTERACTIONS IN CHINA. International Archives of the Photogrammetry, Remote Sensing \& Spatial Information Sciences 2015. 